\title{
Modelling of chloride penetration into non-saturated concrete: Case study application for real marine offshore structures
}

\author{
A. da Costa ${ }^{a}, M$. Fenaux $^{\mathrm{b}, *}$, J. Fernández $^{\mathrm{b}}$, E. Sánchez ${ }^{\mathrm{c}}$, A. Moragues ${ }^{\mathrm{b}}$
}

\begin{abstract}
A B S T R A C T
The aim of this paper is to explain the chloride concentration profiles obtained experimentally from control samples of an offshore platform after 25 years of service life. The platform is located $12 \mathrm{~km}$ off the coast of the Brazilian province Rio Grande do Norte, in the north-east of Brazil. The samples were extracted at different orientations and heights above mean sea level. A simple model based on Fick's second law is considered and compared with a finite element model which takes into account transport of chloride ions by diffusion and convection. Results show that convective flows significantly affect the studied chloride penetrations. The convection velocity is obtained by fitting the finite element solution to the experimental data and seems to be directly proportional to the height above mean sea level and also seems to depend on the orientation of the face of the platform. This work shows that considering solely diffusion as transport mechanism does not allow a good prediction of the chloride profiles. Accounting for capillary suction due to moisture gradients permits a better interpretation of the material's behaviour.
\end{abstract}

\section{Introduction}

Reinforced concrete structures located in very exposed marine environments present corrosion damage [1]. In many cases this damage is worse than those predicted by durability models [2]. In these constructions (bridges, oil platforms, offshore loading docks, etc.), the damages seem to reflect a local exposition effect, depending on orientation and wave action.

The pernicious effect that chloride ions present on the deterioration of reinforced concrete due to its influence on the framework corrosion is a widely known phenomenon. The diffusion coefficient is one of the most used parameters in order to evaluate the material's behaviour to ion chloride penetration. The coefficient should be an intrinsic material parameter, depending only on the materia characteristics and being independent on its external conditions.
When experimental studies are carried out on constructions subjected to marine environments and corrosion damage, chloride penetration profiles of difficult interpretation are found. Assuming that diffusion is the only transport mechanism involved, the position on the structure where samples are found determines appreciably different diffusion coefficients for the same material (same dosage and batch).

Knowledge about the durability of these structures is essential, since the lack of plausible explanations of the mentioned differences is a fact that conditions the repairing projects of this type of constructions. Thus, in many cases, long service periods may only be assured by the use of external and cathode protection, means which considerably difficult the construction and increase the costs of maintenance of these structures [3].

In this work, a real construction subjected to a very exposed marine and tropical climate environment, has been studied after 25 years of service. The presented construction showed framework corrosion damage with very pronounced zonation. 


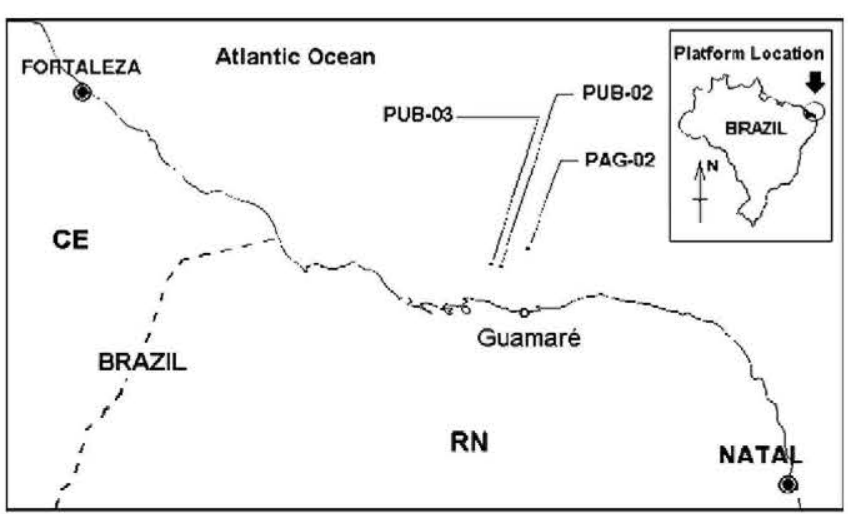

Fig. 1. Concrete oil rigs location.

There are a large number of works that attempt to predict the material's behaviour to the penetration of aggressive agents, such as $\mathrm{CO}_{2}, \mathrm{Cl}^{-}, \mathrm{O}_{2}$. The majority of these works are based on the analytic solution obtained from Fick's second law [4] or the relationship between the chloride ion concentration and the square root of time described by Tuutti [5]. Models basically differ in the applied simplifications and the boundary conditions used solving the differential equations [6,7].

In most of the real situations, chloride transport is not attributed exclusively to a diffusion mechanism. Indeed, the experimental results presented in this work vary significantly in function of the orientation and the height above mean sea level, due to capillary suction. There are a number of authors who propose convection-diffusion models to predict the chloride transport by diffusion and capillary suction mechanisms in concrete [8]. In this paper a chloride penetration model is developed for concretes of 25 years of service life in marine environments. The differences between the experimentally obtained chloride profiles are due to the relative humidity which is directly proportional to the orientation and height above mean sea level.

\section{Materials and methods}

The samples were obtained from a concrete Gravity Based Structure (GBS) for offshore oil production [9]. This structure is located $12 \mathrm{~km}$ away from the coast of the Brazilian province of Rio Grande do Norte, in the north-eastern part of Brazil (Fig. 1).

In this area, the time distribution of wind directions does not show big variations. The predominant directions are East-West (E-W) and North-East South-West (NE-SW).

The E-W direction is predominant between November and April (48\%) and is followed in frequency by the NE-SW direction (26.5\%). Between May and October the predominant direction is NE-SW (51.3\%) followed by the E-W direction (35\%). The winds show low intensity $(13-15 \mathrm{~km} / \mathrm{h})$ from November to April and mild intensity $(20-30 \mathrm{~km} / \mathrm{h})$ from May to October. Waves generally come from the East and are also generated locally. These waves are 0.5 up to $1.0 \mathrm{~m}$ high with a 5 to $8 \mathrm{~s}$ period time. The lower values for the wave periods take place during $\mathrm{Au}-$ gust and September (6-6.5 $\mathrm{s}$ ), while the higher ones (8-18 $\mathrm{s}$ ) appear in January, with predominant direction $\mathrm{N}$ and $\mathrm{NE}$ and with a height of $0.5-2.0 \mathrm{~m}$.

Due to the high temperatures, associated with a short period of rainfall, the region has a BSw'h climate according to Köppe's classification and a warm tropical bio-climate, according to Graussen's classification. The high temperatures persist during the year, being the average annual temperature around $27^{\circ} \mathrm{C}$.

The insolation period is quite high, mainly during the months from August to January, reaching $8.3 \mathrm{~h}$ a day during October and November. The solar exposure time reaches an average of $7.1 \mathrm{~h}$ a day during the months from February to July, which presents the most elevated pluviometric rainfall. The average relative humidity of the air is $70.8 \%$, being lower from June to November.

The chemical characterisation of sea water in the region of the platform shows the following results: saline concentration values between 30 and $35 \%, \mathrm{pH}$ of 8.1 up to 8.4 , dissolved oxygen concentration from 4.6 up to $5.8 \mathrm{ml} / 1$ and a water temperature value of $28 \pm 1^{\circ} \mathrm{C}$, practically constant from the sea level to the sea bottom.

The platforms floor plan dimensions are $46 \mathrm{~m} \times 53 \mathrm{~m}\left(2438 \mathrm{~m}^{2}\right)$ and $25.7 \mathrm{~m}$ of height. These platforms are made of 22 periphery cells for weight balance and 20 central cells, intercommunicated, storing that way $23,000 \mathrm{~m}^{3}$ of oil (Fig. 2).

The specified concrete for the building work had a compressive strength ( $\mathrm{fc} 28$ ) of $35 \mathrm{MPa}$, with a cement content of 450 to $500 \mathrm{~kg} / \mathrm{m}^{3}$ and a maximum w/c ratio of 0.45 (specified value of 0.42 for the side faces). The specified cement type was normal Portland cement, with a maximum C3A content of $8 \%$. The mixing dosage was defined for a w/c ratio of 0.44 ; plastiment "VZ 0.55", $0.05 \%$ "SIKA retarder" and a cement quantity of $490 \mathrm{~kg} / \mathrm{m}^{3}$. The minimum cover of the passive bars was $5 \mathrm{~cm}$ [10,11]. A total amount of 64 samples with a $160 \mathrm{~mm}$ average length were extracted. The sample diameters were $75 \mathrm{~mm}$ in 54 samples and $100 \mathrm{~mm}$ in 10 samples. The samples were extracted from all surfaces except for the eastern one, due to the excessive degradation level of the concrete. The samples were extracted at $4.15 \mathrm{~m}, 7.15 \mathrm{~m}, 7.65 \mathrm{~m}, 9.35 \mathrm{~m}$ and $9.85 \mathrm{~m}$ above mean sea level in the northern side and at $5.35 \mathrm{~m}, 7.35 \mathrm{~m}, 7.85 \mathrm{~m}$ and $9.85 \mathrm{~m}$ above mean sea level in the western side. The samples were subjected to different conditions due to their different heights, i.e.: the sample extracted at $4.15 \mathrm{~m}$ above the mean sea level was more in contact with the seawater than the one extracted at a height of $9.85 \mathrm{~m}$. The latter experienced therefore stronger wetting-drying cycles than the first one. Among the samples, 29 were tested in order to determine the average characteristics of the concrete after 25 years of service. The tests carried out were: cement content test, compression and tensile strength tests (UNE 80304:1986 [12], UNE 83304:1984 [13], UNE 83306:1985 [14]), total porosity and apparent density tests (Mercury Intrusion Porosimetry, MIP) and water penetration test (UNE 83309:90 [15]).

The MIP test was carried out throughout a porosimeter (Porosimeter 2000 Carlo Erba Instruments), with a maximum of $200 \mathrm{MPa}$ and a pore range of $3.7-7500 \mathrm{~nm}$. The intrusion rate was $5 \mathrm{~s}$ for the equilibrium condition. The samples were subjected to a previous degasification during $10 \mathrm{~min}$, throughout vacuum.

The remaining 35 samples were tested in order to determine the chloride concentration profiles according to the standards UNE-EN 196-2:1996 [16] and UNE 112010:1994 [17].

\section{Results}

Table 1a presents the average characteristics of the concrete, according to the test results carried out after 25 years of service life of the structure. The characteristics of the core samples are listed in Table $1 \mathrm{~b}$.

Fig. 3 shows the chloride contents for different penetration depths and different heights above mean sea level, where the reinforced concrete samples were extracted from the lateral faces of the platform.

At first, the penetration profiles are interpreted assuming that diffusion is the only mechanism involved, and that the concrete

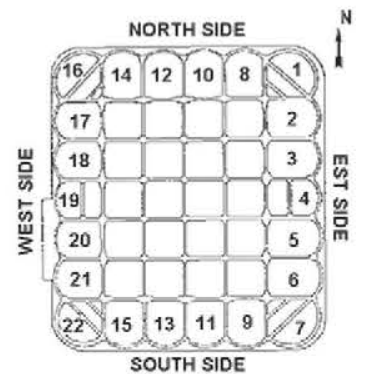

Horizontal Section View

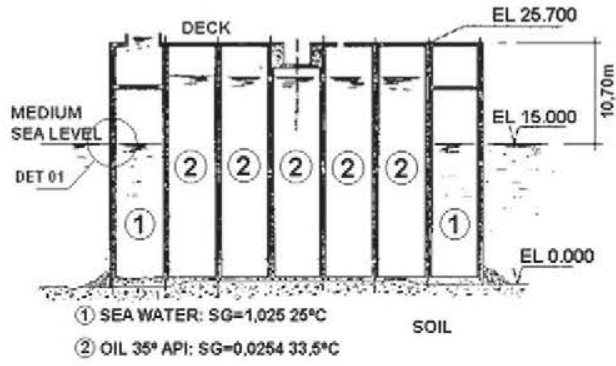

Vertical Section View

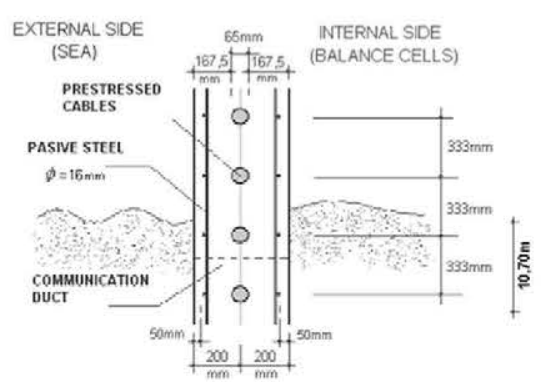

Cross Section View

Fig. 2. Concrete oil rigs details of design. 
Table 1a

Average concrete characteristics after 25 years of service life.

\begin{tabular}{llll}
\hline \multirow{2}{*}{ Characteristics } & Values & & \\
\cline { 2 - 4 } & Maximum & Average & Minimum \\
\hline Cement content $\left(\mathrm{kg} / \mathrm{m}^{3}\right)$ & 600.0 & 526.1 & 495.0 \\
Compressive strength $(\mathrm{MPa})$ & 63.3 & 56.9 & 50.1 \\
Tensile strength $(\mathrm{MPa})$ & 4.4 & 4.1 & 3.8 \\
Total porosity $(\%)$ & 13.5 & 11.3 & 8.5 \\
Apparent density $\left(\mathrm{g} / \mathrm{m}^{3}\right)$ & 2.4 & 2.3 & 2.3 \\
Water penetration $(\mathrm{mm})$ & 67 & 40 & 39 \\
\hline
\end{tabular}

Table 1b

Characteristics of the cylindrical core samples.

\begin{tabular}{ll}
\hline Characteristics & Values \\
\hline Cement content (Portland, 8\% C3A) & $490 \mathrm{~kg} / \mathrm{m}^{3}$ \\
Water cement ratio & 0.44 \\
Plastiment VZ 0.55 Sika Retarder & $0.05 \%$ \\
Length & $160 \mathrm{~mm}$ \\
Diameter & $75 \mathrm{~mm}$ \\
\hline
\end{tabular}

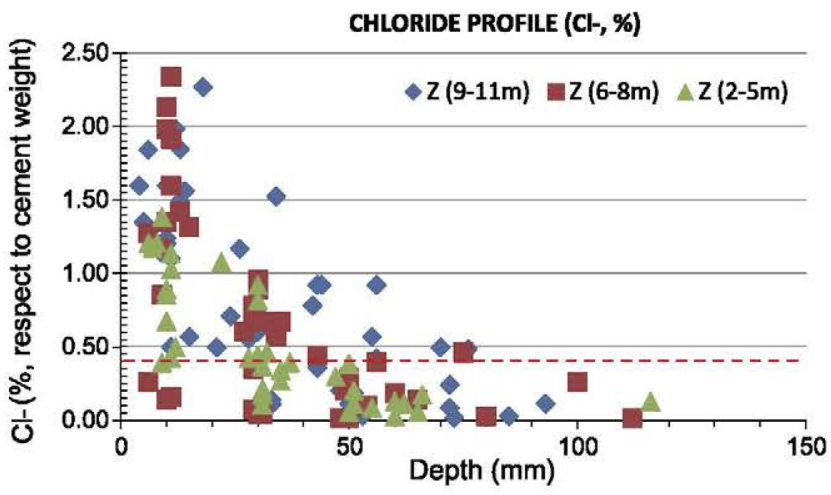

Fig. 3. Chloride content (related to cement mass) at different depths and different heights above main sea level, for both northern and western side.

is fully saturated. Therefore, a one-dimensional diffusion problem is considered, described by Fick's second law which predicts how diffusion causes the concentration to change with time:

$\frac{\partial C(t, x)}{\partial t}=\frac{\partial}{\partial x}\left(D(t, x) \frac{\partial C(t, x)}{\partial x}\right)$

where $C$ is the total chloride ion concentration (\% by mass of concrete), $D$ the apparent diffusion coefficient $\left(\mathrm{m}^{2} / \mathrm{s}\right), x$ the depth $(\mathrm{m})$ and $t$ the time (s).

Assuming that $D$ is a constant, independent of position variable $x$, time $t$, and concentration $C$, reduces Eq. (1) to:

$\frac{\partial C(t, x)}{\partial t}=D \frac{\partial^{2} C(t, x)}{\partial x^{2}}$

The analytic solution of Eq. (2) under assumptions of homogeneous concrete, constant surface concentration and one dimensional diffusion into a semi-infinite space is:

$C(t, x)=C_{0}+\left(C_{s}-C_{0}\right) \operatorname{erfc}\left(\frac{x}{2 \sqrt{D t}}\right)$

where $C_{0}=C(0, x)$ and $C_{s}=C(t, 0)$ are the initial concentration and the surface concentration, respectively. The complementary error function, denoted $\operatorname{erfc}$, is defined as:

$\operatorname{erfc}(z)=\frac{2}{\sqrt{\pi}} \int_{z}^{\infty} e^{-t^{2}} d t$
Table 2

Best-fit diffusion coefficients and surface concentrations, northern side.

\begin{tabular}{lllll}
\hline Sample & Height $(\mathrm{m})$ & $D \times 10^{-13}\left(\mathrm{~m}^{2} / \mathrm{s}\right)$ & $C_{s}(\%$ concrete $)$ & $R$-squared \\
\hline $25 \mathrm{~N}$ & 9.85 & 14.6475 & 0.51 & 0.9060 \\
$26 \mathrm{~N}$ & 9.85 & 10.4260 & 0.62 & 0.9994 \\
$28 \mathrm{~N}$ & 9.85 & 11.5176 & 0.83 & 0.9855 \\
$32 \mathrm{~N}$ & 9.35 & 15.9925 & 0.19 & 0.9989 \\
$36 \mathrm{~N}$ & 7.65 & 7.8908 & 0.50 & 0.9998 \\
$39 \mathrm{~N}$ & 7.15 & 4.7382 & 0.60 & 1.0000 \\
$40 \mathrm{~N}$ & 7.15 & 7.3417 & 0.51 & 0.9999 \\
$30 \mathrm{~N}$ & 4.15 & 4.1810 & 0.67 & 0.9988 \\
$41 \mathrm{~N}$ & 4.15 & 4.6455 & 0.84 & 0.9998 \\
\hline
\end{tabular}

The error function solution of Fick's second law was fitted to the experimental chloride concentration profiles. The least squares method was used in order to determine the best-fit diffusion coefficients and surface concentrations. The initial concentration was set to $C_{0}=0.007$ (\% mass concrete) which coincides with the minimum concentration of all the samples. Results of $D$ and $C_{S}$ for the northern side are shown in Table 2. Figs. 4-6 present the error function solution fitted to the experimental data of the northern face for different sections of height.

Results of $D$ and $C_{S}$ for the western side are shown in Table 3. Figs. 7-10 show the error solution (3) fitted to the experimental data of the northern face for different sections of height. The surface concentration was calculated by extrapolating the error function solution. Very different values for the diffusion coefficient at different heights and orientations were obtained. It may be considered that all concretes have the same characteristics, implying that the different sample positions define different environments. Since the studied concrete is not saturated, capillary suction has its influence on the chloride ion ingress as well and should not be ignored.

As can be observed in Tables 2 and 3, the obtained diffusion coefficients vary from 2.7518 to $15.9925 \times 10^{-13} \mathrm{~m}^{2} / \mathrm{s}$. Those coefficients can therefore not be considered as intrinsic material parameters. In addition, note that, if diffusion is not the only mechanism involved, the extrapolation method for determining the surface concentration provides aberrant results for the studied case.

The surface concentration depends on the chloride binding capacity of the concrete, its porosity at the surface, and environmental variables. The value of the bound chloride concentration may be estimated from the existing information on the relationship between bound and free chloride ions [18]. Furthermore, salt crystallization and dissolving phenomena can occur at important heights above mean sea level and influence significantly the surface concentration in wetting-drying conditions.

\section{Discussion}

A general tendency of the diffusion coefficient increasing with height above mean sea level is observed. Diffusion coefficients of the northern side are higher than those of the western side, especially at about $9 \mathrm{~m}$ above mean sea level. In addition, they grouped more clearly in the northern face than in the western face. It is important to point out as well that surface concentrations are much larger in the northern side than in the western side at every studied height.

When a detailed analysis of the results is to be tackled, one can observe that the obtained diffusion coefficients differ up to one order of magnitude. It is difficult to accept such variation knowing that $D$ is an intrinsic parameter.

These results have two plausible explanations. The first approach may be the significant influence of the surface concentration on the calculation of the diffusion coefficient. This concentration, which is difficult to determine, is usually evaluated 


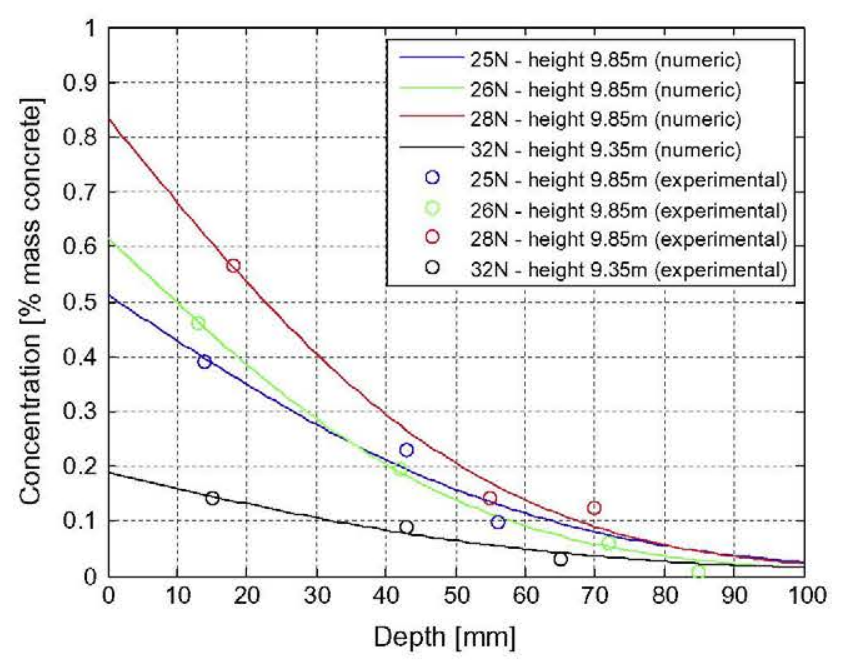

Fig. 4. Chloride ion concentrations from the northern side at a height of 9.35$9.85 \mathrm{~m}$ above mean sea level.

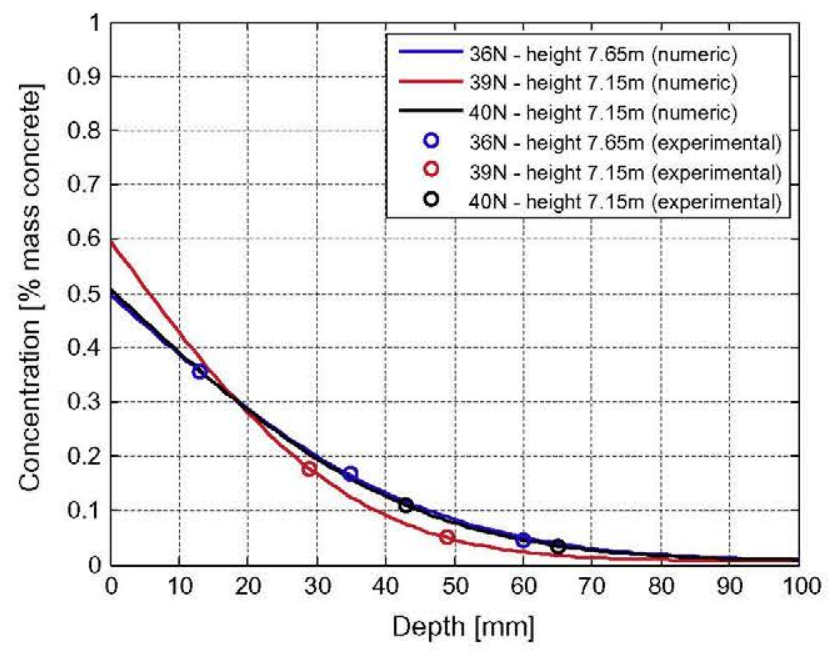

Fig. 5. Chloride ion concentrations from the northern side at a height of 7.15$7.65 \mathrm{~m}$ above mean sea level. Concentrations at a depth less than $1 \mathrm{~cm}$ were ignored in order to eliminate the lixiviation effect.

extrapolating Eq. (3), which leads to a great dispersion of the obtained values for the diffusion coefficient. This fact has been put on relevance by other authors [6] who suggested the use of a new coefficient denominated "diffusivity", defined as the product $D \times C_{s}$, in order to obtain more comparable results. The obtained results for the analysed samples are listed in Table 4 . It seems as if the diffusivity coefficients are directly proportional to the height above mean sea level. However, the practical use of the mentioned parameter presents a double difficulty. On the one hand, it has no physical interpretation and on the other hand, Eq. (3) does not depend on $D$ in the same way as on $C_{s}$. As it may be observed, the same value for the diffusivity coefficient does not imply the same concentration at a given depth: this is obvious comparing the profiles of samples $36 \mathrm{~N}$ and $41 \mathrm{~N}$, which have the same diffusivity coefficients.

The other aspect that justifies the obtained results is that diffusion is not the only mechanism involved. Previous results indicated clearly that diffusion is not the only transport mechanism present. Indeed, capillary suction plays an important role due to the wetting-drying cycles. The higher above the mean sea level, the more intense the cycles are which generates more capillary suction.

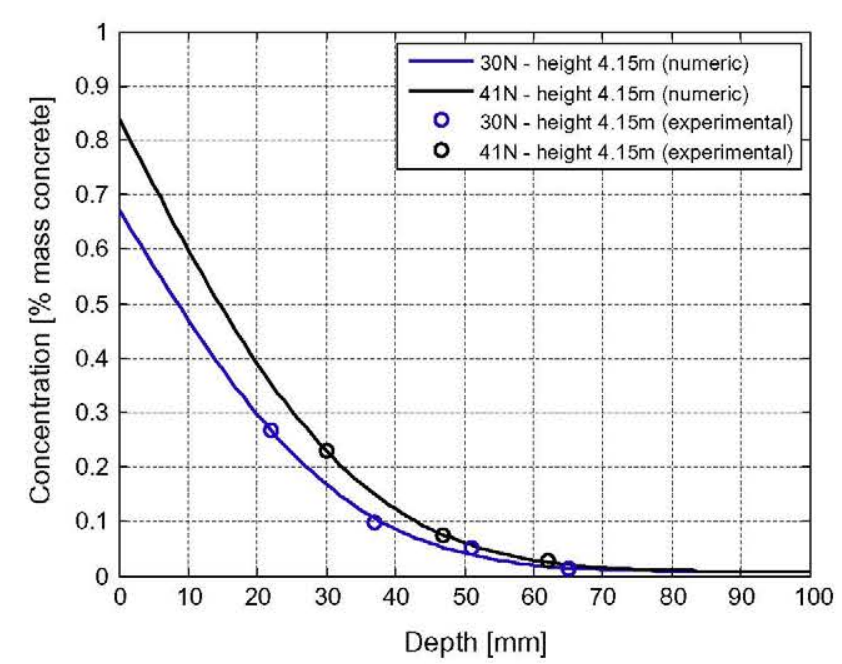

Fig. 6. Chloride ion concentrations from the northern side at a height of $4.15 \mathrm{~m}$ above mean sea level. Concentrations at a depth less than $1 \mathrm{~cm}$ were ignored in order to eliminate the lixiviation effect.

Equivalently, diffusion coefficients listed in Tables 2 and 3 at lower heights are more representative of the real situation, meaning that Eq. (3) gives much better results near the sea level. Tables 2 and 3 show that, at heights near the mean sea level, the minimum diffusion coefficient is $D=4.1810 \times 10^{-13} \mathrm{~m}^{2} / \mathrm{s}$. Assuming that at that height $(4.15 \mathrm{~m})$, capillary suction is minimum (the concrete is nearly saturated), the real apparent diffusion coefficient should be slightly inferior to $4.1810 \times 10^{-13} \mathrm{~m}^{2} / \mathrm{s}$.

A convection-diffusion model is used in order to achieve a better comprehension of the experimental results. Capillary suction is often modelled by means of a convective term [18]. When concrete absorbs liquid water containing chlorides due to capillary suction, the ions are transported by the convective flow of the pore solution. The convection-diffusion problem depends on the convection velocity and the diffusion coefficient. As mentioned before, the latter should not be influenced by the environment and should be slightly inferior to $4.1810 \times 10^{-13} \mathrm{~m}^{2} / \mathrm{s}$. Therefore, one single diffusion coefficient was used and was chosen to be $D=4 \times 10^{-13} \mathrm{~m}^{2} / \mathrm{s}$. The initial condition $C_{0}$ was set to $C_{0}=0.007 \%$ as in the diffusion model.

Several authors propose convection-diffusion models in order to predict chloride ion transport into non-saturated concrete. The convection term of the convection-diffusion problem used by Guzman et al. [18] is:

$$
\nabla \cdot\left(C_{f} D_{h} \nabla h\right)
$$

where $h$ is the relative humidity, $D_{h}$ the apparent diffusivity that takes into account humidity, temperature and equivalent hydration time, and $C_{f}$ the free chloride concentration. Since no humidity tests

Table 3

Best-fit diffusion coefficients and surface concentrations of the western side.

\begin{tabular}{lllll}
\hline Sample & Height $(\mathrm{m})$ & $D \times 10^{-13}\left(\mathrm{~m}^{2} / \mathrm{s}\right)$ & $C_{s}(\%$ concrete $)$ & $R$-squared \\
\hline 02W & 9.85 & 8.0176 & 0.39 & 0.9859 \\
03W & 9.85 & 6.0386 & 0.37 & 0.9999 \\
05AW & 7.85 & 7.2962 & 0.54 & 0.9861 \\
06AW & 7.85 & 7.2252 & 0.44 & 1.0000 \\
05BW & 7.35 & 2.7518 & 0.41 & 0.9930 \\
06BW & 7.35 & 3.6973 & 0.89 & 1.0000 \\
09W & 5.35 & 4.3565 & 0.38 & 0.9870 \\
10W & 5.35 & 6.7360 & 0.22 & 1.0000 \\
11W & 5.35 & 5.8117 & 0.28 & 1.0000 \\
\hline
\end{tabular}




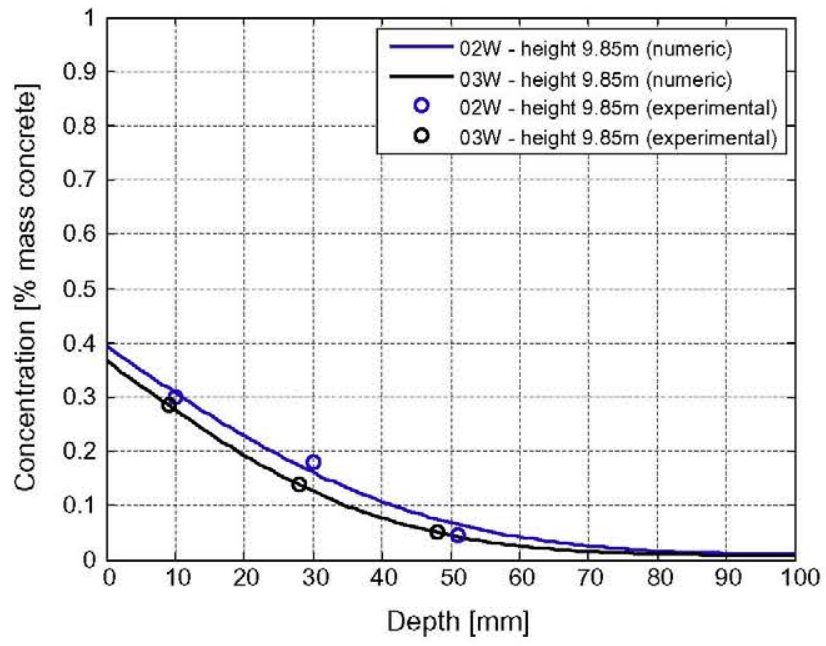

Fig. 7. Chloride ion concentrations from the western side at a height of $9.85 \mathrm{~m}$ above mean sea level.

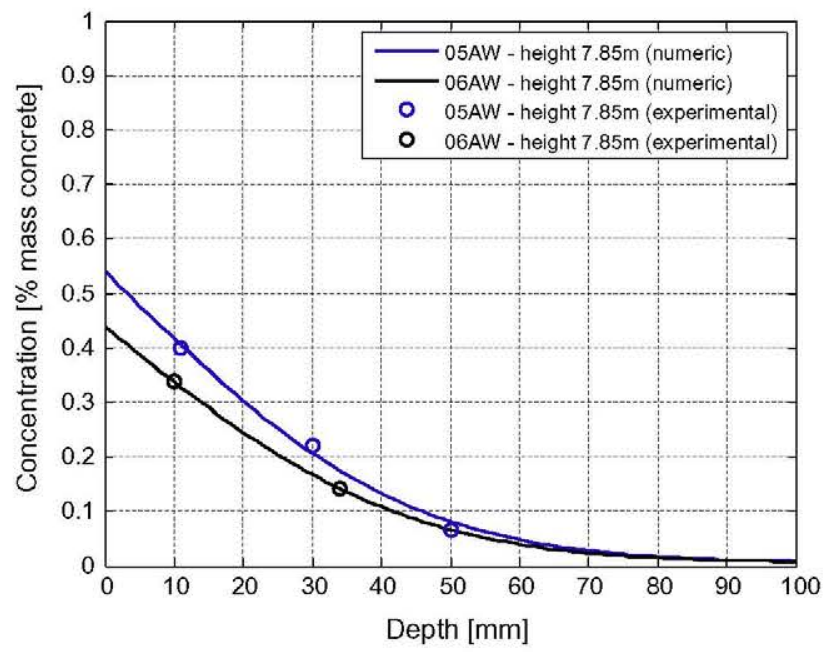

Fig. 8. Chloride ion concentrations from the western side at a height of $7.8 \mathrm{~m}$ above mean sea level.

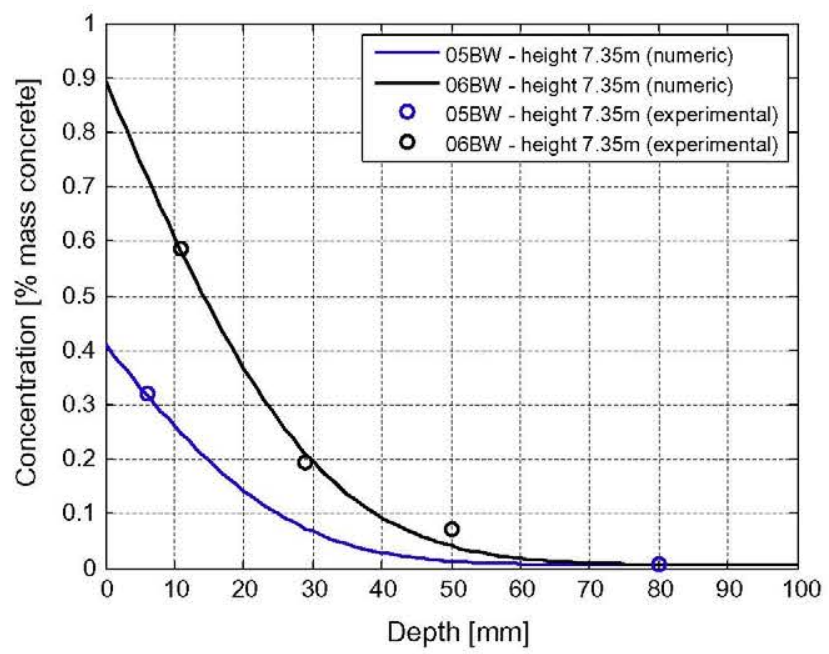

Fig. 9. Chloride ion concentrations from the western side at a height of $7.35 \mathrm{~m}$ above mean sea level.
Table 4

Diffusivity coefficient for the studied profiles.

\begin{tabular}{lll}
\hline Sample & Height $(\mathrm{m})$ & Diffusivity $\times 10^{-13}$ \\
\hline Northern side & & \\
$25 \mathrm{~N}$ & 9.85 & 7.4702 \\
$26 \mathrm{~N}$ & 9.85 & 6.4641 \\
$28 \mathrm{~N}$ & 9.85 & 9.5596 \\
$32 \mathrm{~N}$ & 9.35 & 3.0386 \\
$36 \mathrm{~N}$ & 7.65 & 3.9454 \\
39N & 7.15 & 2.8429 \\
$40 \mathrm{~N}$ & 7.15 & 3.7443 \\
30N & 4.15 & 2.8013 \\
$41 \mathrm{~N}$ & 4.15 & 3.9022 \\
Western side & & \\
02W & 9.85 & 3.1269 \\
03W & 9.85 & 2.2343 \\
$05 \mathrm{AW}$ & 7.85 & 3.9399 \\
06AW & 7.85 & 3.1791 \\
05BW & 7.35 & 1.1282 \\
06BW & 7.35 & 3.2906 \\
09W & 5.35 & 1.6555 \\
10W & 5.35 & 1.4819 \\
$11 \mathrm{~W}$ & 5.35 & 1.6273 \\
\hline
\end{tabular}

were performed on the samples, the convection term was taken to be:

$-u \nabla C$

The one-dimensional convection-diffusion equation for divergence-free velocity field is given by:

$\frac{\partial C(t, x)}{\partial t}+u \frac{\partial C(t, x)}{\partial x}-\frac{\partial}{\partial x}\left(D(t, \cdot x) \frac{\partial C(t, x)}{\partial x}\right)=0$

$\frac{\partial u}{\partial x}=0$

As in the diffusion model, the apparent diffusion coefficient is taken to be a constant, which reduces Eq. (7) to:

$\frac{\partial C(t, x)}{\partial t}+u \frac{\partial C(t, x)}{\partial x}-D \frac{\partial^{2} C(t, x)}{\partial x^{2}}=0$

Eq. (9) was solved by means of the finite element method, implemented in MATLAB, using a Taylor series expansion for the time discretization and a classical Galerkin formulation for the space discretization.

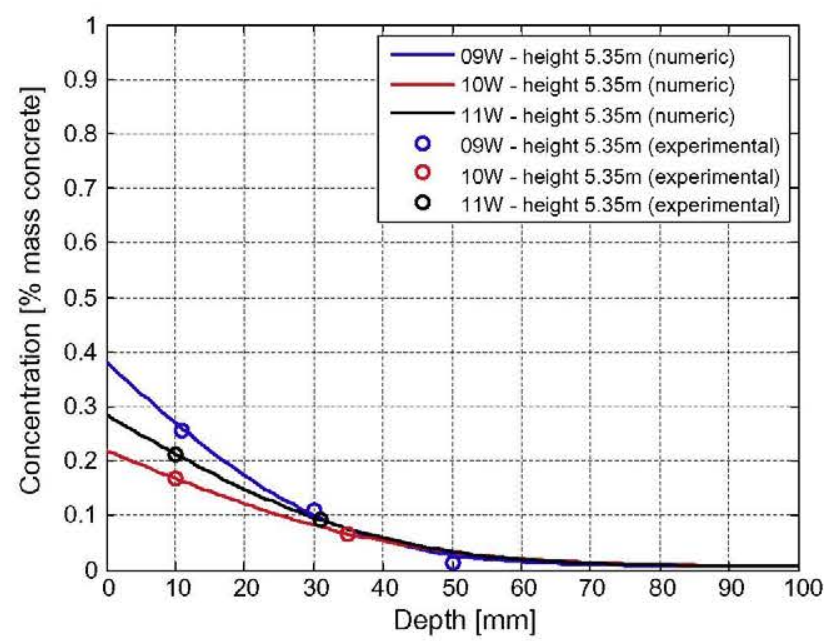

Fig. 10. Chloride ion concentrations from the western side at a height of $5.35 \mathrm{~m}$ above mean sea level. 
Table 5

Best-fit convection velocities and surface concentrations, northern side.

\begin{tabular}{llll}
\hline Sample & Height $(\mathrm{m})$ & $u \times 10^{-11}(\mathrm{~m} / \mathrm{s})$ & $C_{s}$ (\% concrete) \\
\hline $25 \mathrm{~N}$ & 9.85 & 4.2 & 0.44 \\
$26 \mathrm{~N}$ & 9.85 & 4.0 & 0.50 \\
$28 \mathrm{~N}$ & 9.85 & 4.5 & 0.65 \\
$32 \mathrm{~N}$ & 9.35 & 4.5 & 0.16 \\
$36 \mathrm{~N}$ & 7.65 & 2.4 & 0.43 \\
$39 \mathrm{~N}$ & 7.15 & 2.0 & 0.350 \\
$40 \mathrm{~N}$ & 7.15 & 2.5 & 0.40 \\
$30 \mathrm{~N}$ & 4.15 & 1.5 & 0.48 \\
$41 \mathrm{~N}$ & 4.15 & 1.7 & 0.52 \\
\hline
\end{tabular}

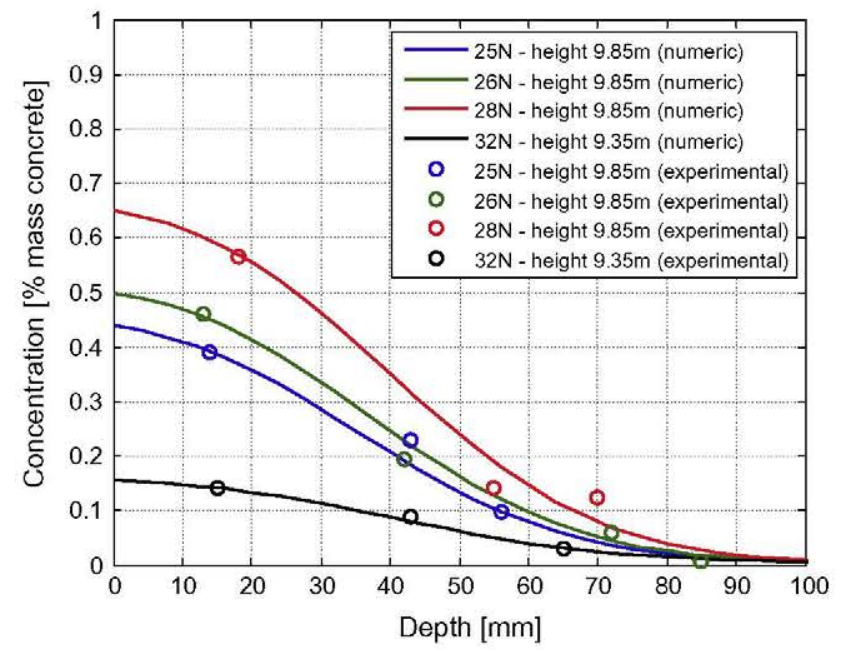

Fig. 11. Chloride ion concentrations from the northern side at a height of 9.35$9.8 \mathrm{~m}$ above mean sea level.

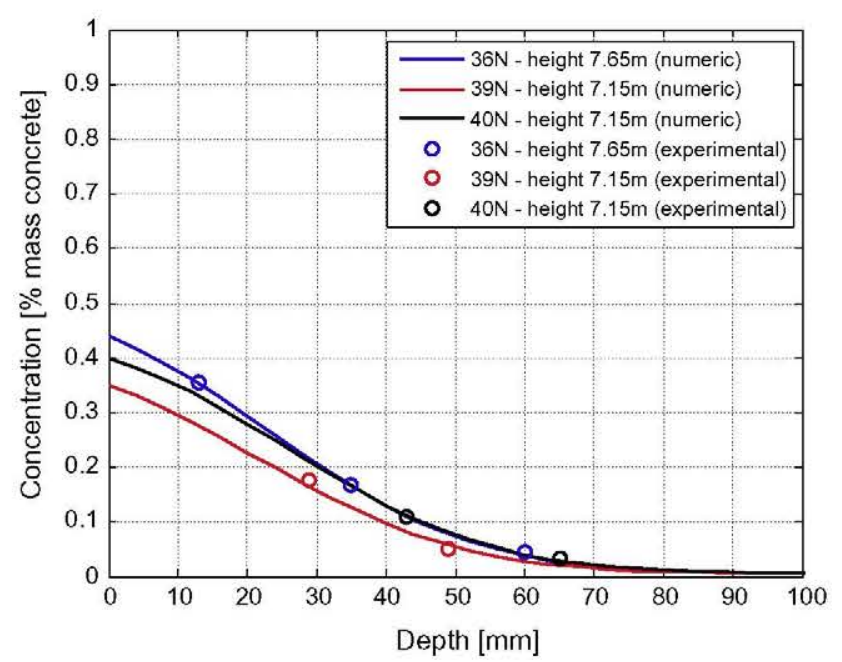

Fig. 12. Chloride ion concentrations from the northern side at a height of 7.15$7.65 \mathrm{~m}$ above mean sea level. Concentrations at a depth less than $1 \mathrm{~cm}$ were ignored in order to eliminate the lixiviation effect.

The finite element solution of the convection-diffusion problem was then fitted to the experimentally obtained data, in order to obtain the convection velocity and the surface concentration. Results of $u$ and $C_{s}$ for the northern side are listed in Table 5. Figs. 11-13 show the finite element solution fitted to the experimental data.

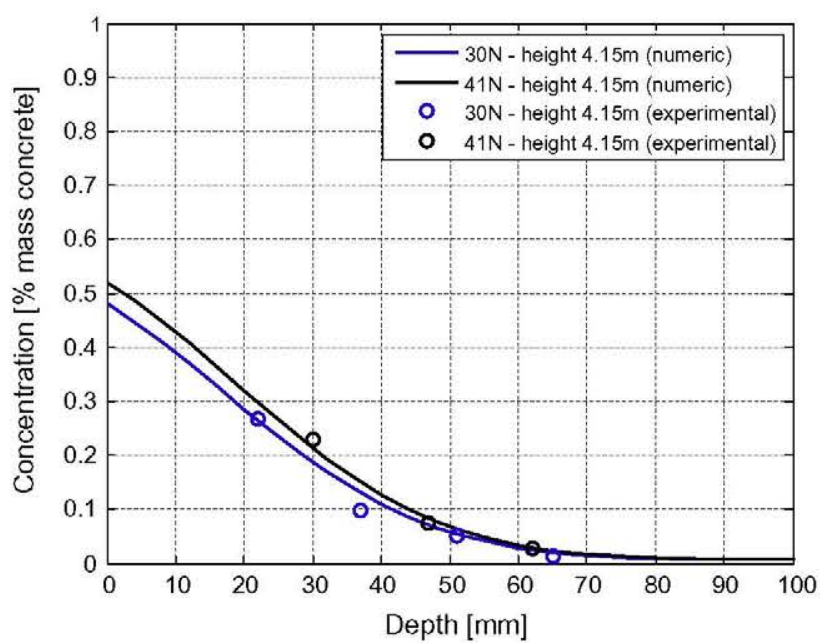

Fig. 13. Chloride ion concentrations from the northern side at a height of $4.15 \mathrm{~m}$ above mean sea level. Concentrations at a depth less than $1 \mathrm{~cm}$ were ignored in order to eliminate the lixiviation effect.

Table 6

Best-fit convection velocities and surface concentrations, western side.

\begin{tabular}{llll}
\hline Sample & Height $(\mathrm{m})$ & $u \times 10^{-11}(\mathrm{~m} / \mathrm{s})$ & $C_{s}(\%$ concrete $)$ \\
\hline 02W & 9.85 & 2.1 & 0.36 \\
03W & 9.85 & 1.6 & 0.34 \\
05AW & 7.85 & 1.7 & 0.49 \\
06AW & 7.85 & 1.7 & 0.41 \\
05BW & 7.35 & 1.2 & 0.36 \\
06BW & 7.35 & 1.2 & 0.70 \\
09W & 5.35 & 0.8 & 0.35 \\
10W & 5.35 & 1.5 & 0.21 \\
11W & 5.35 & 1.1 & 0.27 \\
\hline
\end{tabular}

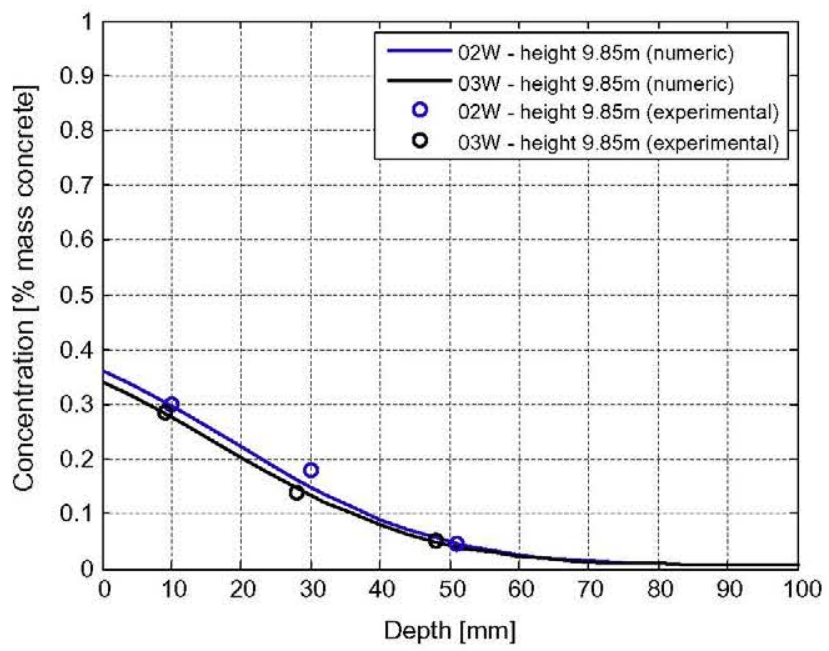

Fig. 14. Chloride ion concentrations from the western side at a height of $9.85 \mathrm{~m}$ above mean sea level.

Results of $u$ and $C_{s}$ for the western side are shown in Table 6 . Figs. 14-17 show corresponding curves.

The results show that the convection velocity increases with height, as expected. It is important to highlight the fact that the surface concentration does not determine the behaviour of the material. For instance, comparing profiles from the same side and the same height, like 05BW and 06BW (Fig. 16), shows clearly that 


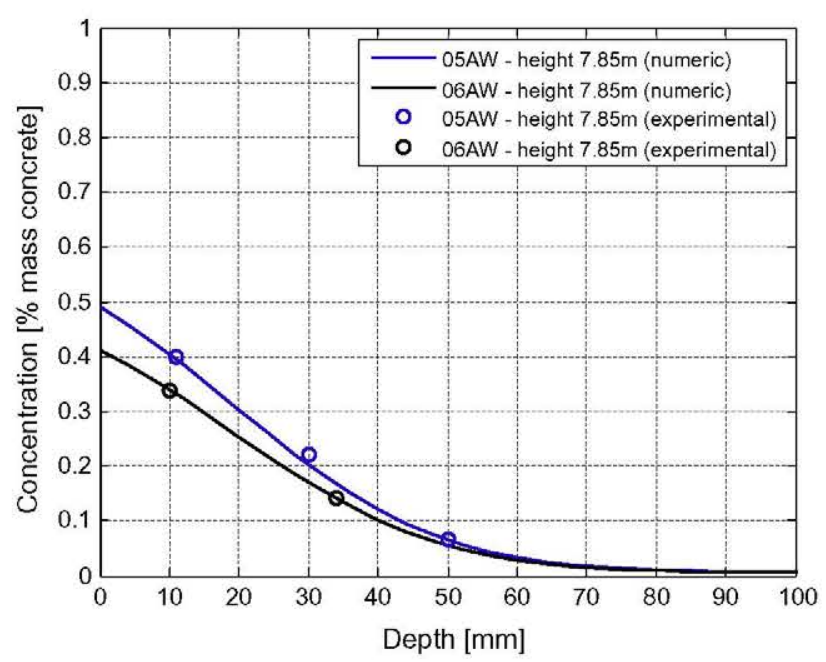

Fig. 15. Chloride ion concentrations from the western side at a height of $7.8 \mathrm{~m}$ above mean sea level.

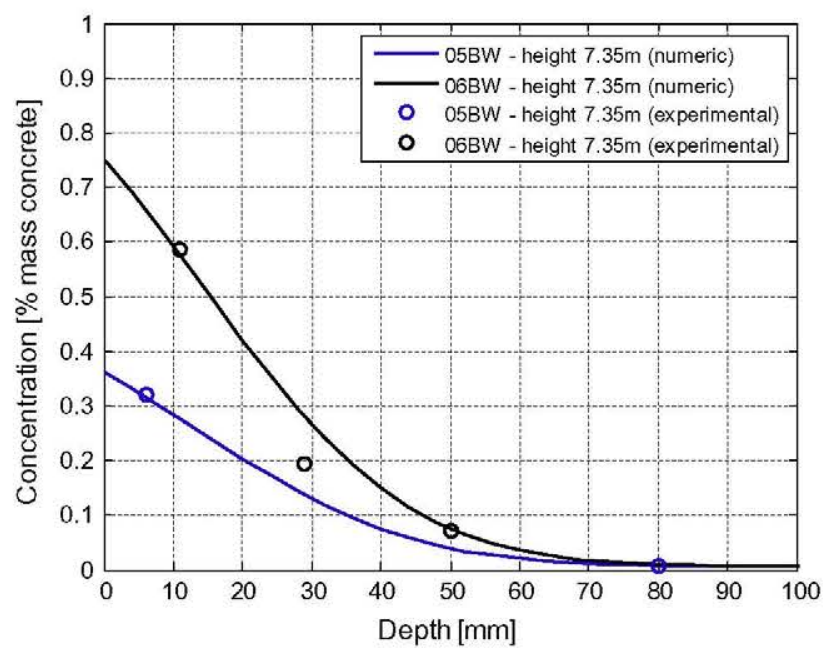

Fig. 16. Chloride ion concentrations from the western side at a height of $7.35 \mathrm{~m}$ above mean sea level.

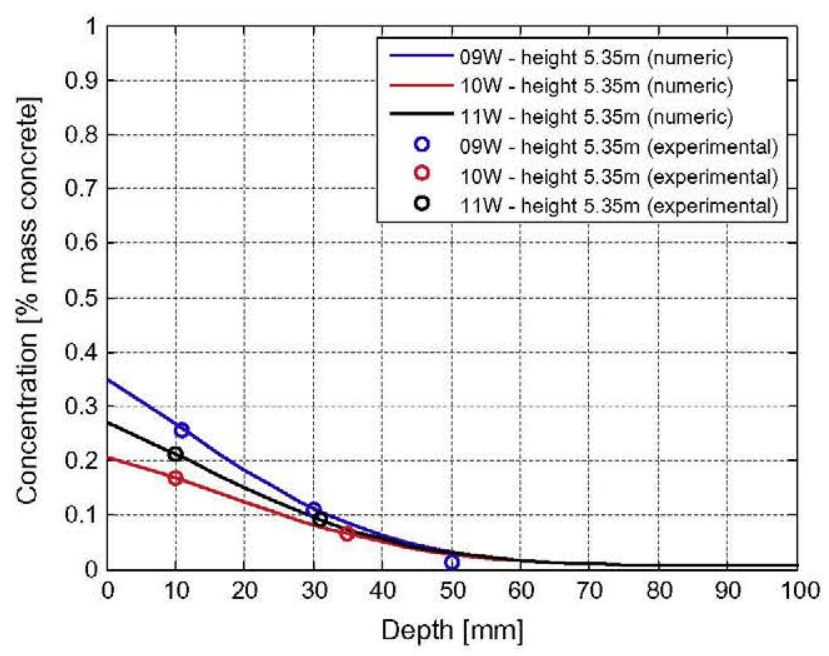

Fig. 17. Chloride ion concentrations from the western side at a height of $5.35 \mathrm{~m}$ above mean sea level.

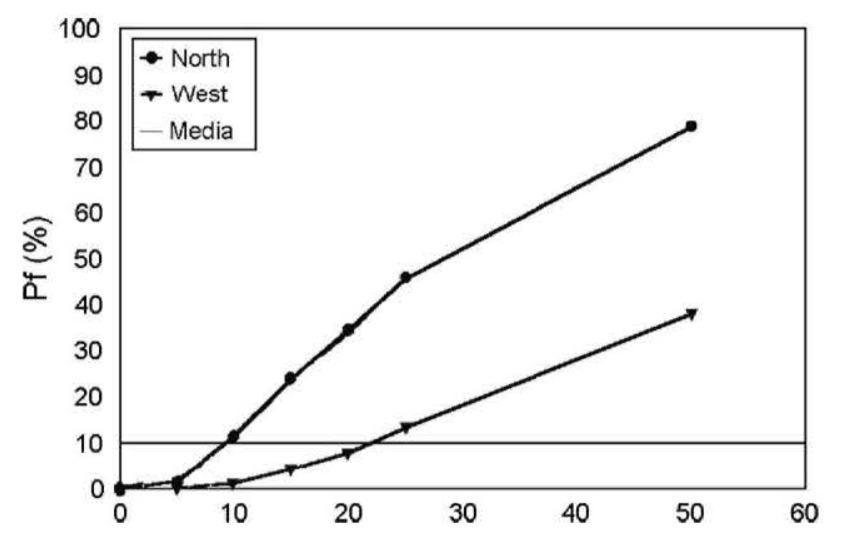

Fig. 18. Probability for the chloride ions to reach the rebar with a concentration of $0.4 \%$ with respect to cement mass in function of time.

the model adjusts to the experimental data using the same values for $D$ and $u$ and different values for $C_{s}$. These different values for $C_{s}$ can be attributed to salt crystallization and different surface pore sizes.

Furthermore, one can easily see that the convection velocity in the northern side of the platform is about double the velocity in the western side. This can be explained by the wetting-drying cycles which are much stronger in the northern side due to the trade wind. Fig. 18 represents the probability for the chloride ions to reach the rebar with a concentration of $0.4 \%$ with respect to cement mass in function of time $[19,20]$. The failure probability exceeds $10 \%$ for 10 years of service life in the northern side and for 22 years of service life in the western side. This is in agreement with the difference between the convection velocities in the northern and those in the western side of the platform.

\section{Conclusions}

Chloride penetration into non-saturated concrete cannot be represented exclusively by diffusion transport mechanisms.

The application of the model which considers simultaneously diffusion and convection as transport mechanisms in specimens obtained from an oil platform offshore leads to the following conclusions:

Considering simultaneously diffusion and convection in order to explain chloride penetration in non-saturated conditions in marine environments, allows a better understanding of the experimentally obtained chloride profiles and a better evaluation of the material's resistance to chloride transport.

Modelling chloride ion transport considering simultaneously diffusion and convection permits the use of an intrinsic diffusion coefficient of the material. The variations observed in the chloride profiles can be interpreted by the change of the interior humidity which is determined by the different environmental conditions. These different environments are taken into account by means of the convection velocity which is directly proportional to the height above mean sea level.

The convection velocity depends on the orientation of the face of the platform as well. This is due to the different wave actions. Indeed, the waves are more intense in the northern side than in the western side.

Extrapolating the error solution results in overestimated values for the surface concentration. By consequence, this leads to overrating the resistance to chloride penetration of the material in terms of the diffusion coefficient. Application of the latter would then overestimate the service life of the concrete structure. 


\section{References}

[1] Fernández Cánovas M. Patología y Terapéutica del Hormigón Armado. Servicio de Publicaciones de la Escuela de Caminos UPM, 3a Ed. Madrid. Spain; 1994.

[2] Marchand J, Samson E. Predicting the service-life of concrete structures limitations of simplified models. Cem Concr Compos 2009;31(September): 515-21.

[3] McArthur H, D'Arcy S, Barker J. Cathodic protection by impressed DC currents for construction, maintenance and refurbishment in reinforced concrete. Cem Concr Res 1993; 7:85-93.

[4] Luping T, Gulikers J. On the mathematics of time-dependent apparent chloride diffusion coefficient in concrete. Cem Concr Res 2007;37:595-8.

[5] Tuutti K. Corrosion of steel in concrete, swedish cement and concrete research institute (CBI), Report Fo 4.82. Stockholm; 1982.

[6] Andrade C, Castellote M, Tavares F, Petre-Lazars I, Climent MA. The key role of surface concentration in the modelling of chloride penetration into concrete. In: International cement chemistry congress. Montreal, Canada; 2007.

[7] Andrade C, Tavares F, Castellote M, Petre-Lazars I, Climent MA, Vera G. Comparison of chloride models: the importance of surface concentration. Bagneux, France: Rilem Publications; 2006. p. 227-242.

[8] Conciatori D, Sadouki H, Brühwiler E. Capillary suction and diffusion model for chloride ingress into concrete. Lausanne, Switzerland: Swiss Federal Institute of Technology (EPFL); 2008.

[9] A. Pereira, Estudio de Métodos Probabilísticos para la Predicción de la Vida Ûtil de Estructuras de Hormigón: Importancia del Factor Variabilidad Espacial en el
Caso de Plataformas Offshore en Brasil. Doctoral thesis, Universidad Politécnica de Madrid, E.T.S.I. de Caminos, Canales y Puertos, Madrid. Spain; 2003.

[10] DNV. Technical report: construction of PUB-02, PUB-03 y PAG-02 oil rigs, Det Norsk Veritas, Petrobrás, Brazil; 1976-1977-1978.

[11] DNV. Inspection plan of PAG-02 concrete oil rig: technical report, Det Norsk Veritas, (Report no. 450-001/87), Petrobrás, Brasil; 1987.

[12] UNE 80304:1986. Cementos. Cálculo de la composición potencial del Clinker Portland. AENOR; 1986.

[13] UNE 83304:1984. Ensayos de hormigón. Rotura por compresión. AENOR; 1984

[14] UNE 83306:1985. Ensayos de hormigón. Rotura por tracción indirecta. (Ensayo brasileño).

[15] UNE 83309:1990. Ensayos de hormigón. Determinación de la profundidad de penetración de agua bajo presión. AENOR; 1990.

[16] UNE-EN 196-2:1996. Métodos de ensayo de cementos. Parte 2: Análisis químico de cementos. AENOR; 1996.

[17] UNE 112010:1994. Corrosión en armaduras. Determinación de cloruros en hormigones endurecidos y puestos en servicio. AENOR; 1994.

[18] Guzman S, Gálvez JC, Sancho JM. Cover cracking of reinforced concrete due to rebar corrosion induced by chloride penetration. Cem Concr Res 2010.

[19] Pereira A, Fernández J, Moragues A. Avaliaçao da Variabilidade Espacial na Previsao da Vida Útil Segundo Proposta Probabilística: Caso de Plataformas, Offshore no Brasil. HOLOS, IFRN 2010:3:46-57.

[20] Da Costa A, Moragues A, Fernández J. Estudio de la variabilidad en las características de transporte con 25 años de vida en servicio en ambiente offshore tropical. Chile: Pontificia Universidad de Chile; 2003. 